\title{
Inhibition of the absorption of paraquat from the gastrointestinal tract by adsorbents
}

\author{
D. G. CLARK \\ Imperial Chemical Industries Limited, Industrial Hygiene Research Laboratories, \\ Alderley Park, near Macclesfield, Cheshire
}

\begin{abstract}
Clark, D. G. (1970). Brit. J. industr. Med., 27, 186-188. Inhibition of the absorption of paraquat from the gastrointestinal tract by adsorbents. The efficacy of the oral administration of adsorbents Kaolin, Decalso, Amberlite, Bentonite and Fuller's Earth in preventing the toxic actions of ingested paraquat (1, '1'-dimethyl-4,4'-dipyridylium) has been assessed using rats and cats. Only Bentonite and Fuller's Earth were found to have any effect, and they were both more effective than a simple stomach wash. It is suggested that these materials may be useful as immediate antidotes to paraquat poisoning in man. Fuller's Earth is preferable to Bentonite as it can be used as a more concentrated suspension, leading to a beneficial reduction in therapeutic volume.
\end{abstract}

Ingestion of the herbicide paraquat $\left(1,1^{\prime}\right.$-dimethyl$4,4^{\prime}$-dipyridylium) can give rise to marked toxic effects in both animals and man (Clark, McElligott, and Hurst, 1966; Bullivant, 1966). In the absence of a specific antidote to reverse these effects, treatment in man has been directed towards hastening the elimination of paraquat from the blood stream by various means such as forced diuresis (Kerr, Patel, Scott, and Tompsett, 1968) and peritoneal dialysis (Oreopoulos, Soyannwo, Sinniah, Fenton, McGeown, and Bruce, 1968).

Another way to approach the problem, however, would be to try to prevent paraquat reaching the blood stream by hindering its absorption from the gastrointestinal tract. This approach has been advocated in the treatment of poisoning by aspirin, apomorphine, etc., for instance, the reduction in absorption from the gastrointestinal tract being brought about by adsorption of the poison by active charcoal (Decker, Shpall, Corby, Combs, and Payne, 1969). Although active charcoal is unable to adsorb paraquat, the fact that paraquat is firmly adsorbed by soil (Knight and Tomlinson, 1967) indicated that materials may be found that would adsorb paraquat in the gastrointestinal tract. Accordingly, this paper deals with the investigation of the adsorption of paraquat by various materials in the gastrointestinal tract of animals, and their efficacy in preventing paraquat poisoning.

\section{Materials and methods}

Acute oral toxicity was determined in female rats of the Alderley Park albino strain (body weights 150 to $200 \mathrm{~g}$ ).

Absorption of paraquat from the gastrointestinal tract was assessed by measuring blood levels after oral administration in the cat. Male cats ( 2 to $4 \mathrm{~kg}$ body weight), that had been fasted overnight, were anaesthetized with $80 \mathrm{mg} / \mathrm{kg}$ chloralose intravenously, the trachea was cannulated and a stomach tube inserted via the oesophagus. Blood was taken from a cannulated carotid artery. The stomach was washed, via the stomach tube, with four washes of $25 \mathrm{ml}$ water.

Paraquat in blood and aqueous solution was analysed by the method of Daniel and Gage (1966), the sensitivity being $1.0 \mu \mathrm{g} / \mathrm{ml}$. The following adsorbents were used suspended in water:

Fuller's Earth (Fuller's Earth, Surrey finest powder, Laporte Industries Ltd, Redhill, Surrey) is also known as calcium montmorillonite and Sub-Bentonite. 
Bentonite (Bentonite B.P.) is also known as sodium montmorillonite, Wilkinite and Clay Soap.

Kaolin (Kaolin B.P.)

Decalso (Synthetic sodium aluminium silicate, Permutit Co. Ltd. London).

Amberlite (AG50W-X8 cation exchange resin, 100 to 200 mesh, in the sodium form, Dow Chemicals).

A solution of commercial Gramoxone W, containing $20 \%$ paraquat, was used throughout the experiments. All results are expressed as the paraquat ion.

\section{Results}

Adsorbents and paraquat mortality in the rat Preliminary in vitro experiments were conducted to compare the ease with which the various materials adsorbed paraquat. The measure of adsorption used was the strong adsorption capacity (SAC), which is defined as the quantity of paraquat that can be adsorbed per unit weight of adsorbent before the adsorbed phase is in equilibrium with a detectable solution concentration (Knight and Tomlinson, 1967), in this instance $1 \mu \mathrm{g} / \mathrm{ml}$. Paraquat was adsorbed on Amberlite by passing a paraquat solution through a column of Amberlite; the other adsorbents were shaken with paraquat solutions for 10 minutes.

TABLE 1

The Strong Adsorption Capacities of VARIOUS MATERIALS

\begin{tabular}{|c|c|c|}
\hline Adsorber & & $S A C$ ( $g$ paraquat $/ 100 \mathrm{~g}$ adsorbent) \\
\hline $\begin{array}{lr}\text { Kaolin } & . \\
\text { Decalso } & . \\
\text { Amberlite } & . \\
\text { Bentonite } & . \\
\text { Fuller's } & \text { Earth }\end{array}$ & $\begin{array}{l}\ldots \\
\cdots \\
\cdots \\
\cdots \\
\ldots\end{array}$ & $\begin{array}{l}0.5 \\
1.4 \\
1.7 \\
5.0 \\
5.0\end{array}$ \\
\hline
\end{tabular}

Using this information (Table 1), suspensions of each adsorbent were prepared containing the maximum amount of paraquat that could be adsorbed without exceeding the SAC. The suspensions were then given by stomach tube to groups of rats, each rat receiving $150 \mathrm{mg} / \mathrm{kg}$ of adsorbed paraquat.

TABLE 2

Mortality after AN Oral Dose of $150 \mathrm{mg} / \mathrm{kg}$ ADSORBED PARAQuAT

\begin{tabular}{|c|c|c|c|c|c|c|}
\hline \multicolumn{6}{|c|}{ Adsorbent } & Mortality \\
\hline $\begin{array}{l}\text { None ... } \\
\text { Kaolin .. } \\
\text { Amberlite } \\
\text { Decalso } \\
\text { Bentonite } \\
\text { Fuller's Earth }\end{array}$ & $\begin{array}{l}\cdots \\
\cdots \\
\cdots \\
\cdots \\
\cdots\end{array}$ & $\begin{array}{l}\cdots \\
\cdots \\
\cdots \\
\cdots \\
\cdots \\
\cdots\end{array}$ & $\begin{array}{l}\cdots \\
\cdots \\
\cdots \\
\cdots \\
\cdots\end{array}$ & $\begin{array}{l}\cdots \\
\cdots \\
\cdots \\
\cdots \\
\cdots \\
\cdots\end{array}$ & $\begin{array}{l}\cdots \\
\cdots \\
\cdots \\
\cdots \\
\cdots\end{array}$ & $\begin{array}{l}5 / 10 \\
4 / 10 \\
0 / 10 \\
0 / 10 \\
0 / 10 \\
0 / 10\end{array}$ \\
\hline
\end{tabular}

The 14-day mortality data (Table 2) show that this dose of paraquat, equivalent to an $\mathbf{L D}_{50}$ dose, is not lethal when adsorbed on Amberlite, Decalso, Bentonite or Fuller's Earth before administration. Adsorption on Kaolin, however, does not reduce the toxicity of paraquat, suggesting that the paraquat is readily desorbed in the gastrointestinal tract to exert its usual toxicity. Consequently, Kaolin was eliminated from the investigations.

The other adsorbents were then studied to see if they could adsorb paraquat in the gastrointestinal tract. Paraquat was administered to groups of rats by stomach tube and the adsorbents were given at various times later. Two doses of paraquat were used: the least dose which killed all the rats in our experiments $(200 \mathrm{mg} / \mathrm{kg})$ and a dose twice the $\mathrm{LD}_{50}$. The dose of each adsorbent was such that its SAC was not exceeded. The results (Table 3) show that

TABLE 3

Mortality due to Oral Paraquat when the AdSORBENTS ARE Given AT VARIOUS TIMES LATER

\begin{tabular}{l|c|c|c}
\hline \multicolumn{1}{c|}{ Adsorbent } & $\begin{array}{c}\text { Time after } \\
\text { paraquat when } \\
\text { adsorbent given } \\
\text { (hr) }\end{array}$ & \multicolumn{2}{|c}{$\begin{array}{c}\text { Paraquat dose and } \\
\text { mortality }\end{array}$} \\
\cline { 2 - 4 } & $-200 \mathrm{mg} / \mathrm{kg}$ & $300 \mathrm{mg} / \mathrm{kg}$ \\
\hline None & - & $6 / 6$ & $6 / 6$ \\
Amberlite & 0.5 & $6 / 6$ & $6 / 6$ \\
Decalso & 0.5 & $6 / 6$ & $6 / 6$ \\
Bentonite & 0.5 & $0 / 6$ & $6 / 6$ \\
& $1 \cdot 0$ & $0 / 6$ & $6 / 6$ \\
& $2 \cdot 0$ & $3 / 6$ & $6 / 6$ \\
Fuller's Earth & 3.0 & $5 / 6$ & $6 / 6$ \\
& 0.5 & $0 / 6$ & $3 / 6$ \\
& 1.0 & $1 / 6$ & $6 / 6$ \\
& 2.0 & $2 / 6$ & $5 / 6$ \\
& 3.0 & $4 / 6$ & $6 / 6$ \\
\hline
\end{tabular}

Amberlite and Decalso are not effective adsorbents of paraquat when given half an hour after paraquat, whereas Bentonite and Fuller's Earth are effective as they can prevent deaths when given one hour after a dose of $200 \mathrm{mg} / \mathrm{kg}$ paraquat. Adsorption onto Bentonite and Fuller's Earth can also occur when they are given up to three hours later, and some deaths can even be prevented after an oral dose of $300 \mathrm{mg} / \mathrm{kg}$ paraquat.

\section{Adsorbents and paraquat blood levels in the cat}

A dose of $62.5 \mathrm{mg} / \mathrm{kg}$ paraquat followed by $10 \mathrm{ml}$ water was administered to groups of four cats by stomach tube; one hour later, Bentonite, Fuller's Earth or a stomach wash was given. Blood was taken at intervals throughout the experiment for the determination of paraquat. The analyses (Figure) show that all treatments led to a marked reduction 


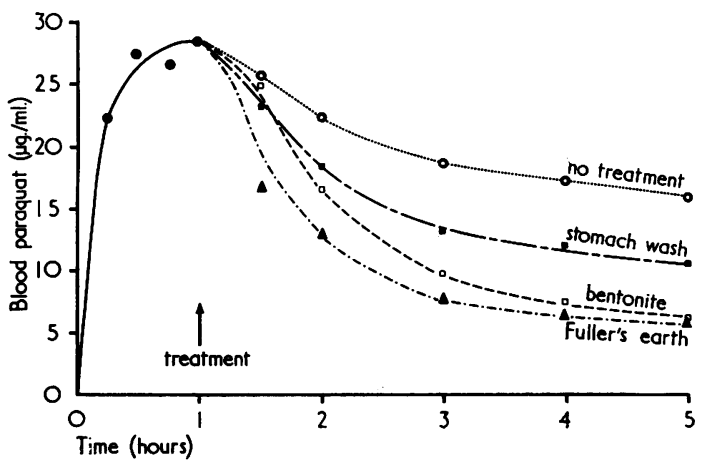

FIGURE Effect of various treatments on the blood levels of paraquat following an oral dose of $62.5 \mathrm{mg} / \mathrm{kg}$ in fasted cats.

in the levels of paraquat in the blood compared with untreated controls.

\section{Discussion}

The results show that although Kaolin, Decalso, Amberlite, Bentonite and Fuller's Earth are capable of adsorbing paraquat in vitro, only Bentonite and Fuller's Earth can adsorb paraquat in vivo. Administration of Bentonite or Fuller's Earth to rats can prevent deaths due to paraquat, and administration to cats can markedly reduce absorption from the gastrointestinal tract. In addition, both these materials are more effective than a stomach wash in reducing absorption, no doubt because a stomach wash only removes paraquat from the stomach whereas the clays are able to adsorb paraquat throughout the gastrointestinal tract. The reason for the failure of the other adsorbents in vivo is most probably due partly to their low adsorption capacities for paraquat and partly to the slowness with which they adsorb paraquat. A material such as Amberlite, which adsorbs paraquat only slowly from a solution passed through a column of it, will obviously be less efficient in adsorbing paraquat in the gastrointestinal tract than Fuller's Earth which adsorbs paraquat firmly after only a few minutes shaking in a flask.

Bentonite and Fuller's Earth might be useful as antidotes in man. There is no point in seeking better adsorbents than these. They are already so good that the success of treatment will depend on how soon they are given after paraquat is swallowed and not upon the speed with which they adsorb it after being given. The experiments with the cat show that absorption from the gastrointestinal tract is rapid enough for peak blood concentrations to be reached in one hour. One cannot therefore emphasize too much the importance of rapid treatment.

Although both Bentonite and Fuller's Earth are equally effective in adsorbing paraquat, Fuller's Earth would be preferable as an antidote as it can be used as a $30 \%$ suspension, whereas Bentonite swells in water and can be used only as a 6 to $7 \%$ suspension. Consequently, a large reduction in therapeutic volume is possible with Fuller's Earth.

In view of the conclusion of Tomlinson, Knight, Bastow, and Heaver (1967) that all herbicidal bipyridylium ions are likely to be adsorbed strongly by clay minerals, Fuller's Earth might also be an effective antidote to poisoning by other bipyridyls such as diquat $\left(1,1^{\prime}\right.$-dimethyl-4,4'-dipyridylium) and morfamquat [1,1'-bis(3,5-dimethylmorpholinocarbonylmethyl)-4,4'-dipyridylium].

\section{References}

Bullivant, C. M. (1966). Accidental poisoning by paraquat: report of two cases in man. Brit. med. J., 1, 1272-1273.

Clark, D. G., McElligott, T. F., and Hurst, E. W. (1956). The toxicity of paraquat. Brit. J. industr. Med., 23, 126-132.

Daniel, J. W., and Gage, J. C. (1966). Absorption and excretion of diquat and paraquat in rats. Brit.J. industr. Med., 23, 133-136.

Decker, W. J., Shpall, R. A., Corby, D. G., Combs, H. F., and Payne, C. E. (1969). Inhibition of aspirin absorption by activated charcoal and apomorphine. Clin. Pharmacol. Therap., 10, 710-713.

Kerr, F., Patel, A. R., Scott, P. D. R., and Tompsett, S. L. (1968). Paraquat poisoning treated by forced diuresis. Brit. med. J., 3, 290-291.

Knight, B. A. G., and Tomlinson, T. E. (1957). The interaction of paraquat (1:1'-dimethyl $4: 4^{\prime}$-dipyridylium dichloride) with mineral soils. $J$. Soil Sci., 18, 233-243.

Oreopoulos, D. G., Soyannwo, M. A. O., Sinniah, R., Fenton, S. S. A., McGeown, M. G., and Bruce, J. H. (1968). Acute renal failure in case of paraquat poisoning. Brit. med. J., 1, 749-750.

Tomlinson, T. E., Knight, B. A. G., Bastow, A. W., and Heaver, A. A. (1967). ICI Agricultural Division Report A. 126,766.

Received for publication May 22, 1970. 